\title{
Pengaruh Kualitas Pelayanan, Citra Merek, dan Persepsi Nilai Terhadap Loyalitas Konsumen Pisang King Rengat
}

\author{
Kurnia Dewi, Airine Yulianda \\ Prodi Manajemen, STIE Indragiri Rengat, Riau, Indonesia \\ Email: 1,"kurniadewi@ @stieindragiri.ac.id, 2airine@stieindragiri.ac.id \\ Email Penulis Korespondensi: kurniadewi@stieindragiri.ac.id \\ Submitted: 08/11/2021; Accepted: 28/11/2021; Published: 30/11/2021
}

\begin{abstract}
Abstrak-Loyalitas pelanggan adalah pelanggan yang tidak hanya membeli ulang suatu barang dan jasa tetapi juga mempunyai komitmen dan sikap yang positif terhadap perusahaan jasa, misalnya dengan merekomendasikan orang lain untuk membeli atau menggunakan jasa tersebut. Kualitas layanan adalah upaya pemenuhan kebutuhan dan keiinginan konsumen berdasarkan apa yang diharapkan oleh konsumen. Citra merek adalah representasi dari keseluruhan persepsi terhadap merek yang dibentuk dari informasi dan pengalaman terhadap merek tersebut. persepsi nilai adalah merupakan penilaian konsumen yang dilakukan dengan cara membandingkan antara manfaat/keuntungan yang akan diterima dengan pengorbanan yang dikeluarkan akan sebuah produk. Jadi persepsi nilai ini berdampak kepada konsumen memutuskan untuk membeli atau menggunakan suatu produk atau jasa. Penelitian ini merupakan penelitian deskriptif kuantitatif dengan sampel dalam penelitian ini adalah konsumen Pisang King Rengat. Penelitian ini bertujuan untuk mengetahui dan menganalisa pengaruh kualitas pelayanan, citra merek dan persepsi nilai terhadap loyalitas konsumen. Kuesioner dan wawancara dilakukan untuk mendapatkan data primer dan beberapa data tambahan digunakan sebagai data primer. Hasil temuan penelitian menyebutkan bahwa kualitas pelayanan, citra merek dan persepsi nilai mempunyai pengaruh positif terhadap loyalitas konsumen pada Pisang King Rengat.
\end{abstract}

Kata Kunci: Kualitas Pelayanan; Citra Merek; Persepsi Nilai; Loyalitas Konsumen

\begin{abstract}
Customer loyalty is a customer who not only repurchases an item and service but also has a positive commitment and attitude towards a service company, for example by recommending others to buy or use the service. Service quality is an effort to fulfill the needs and desires of consumers based on what is expected by consumers. Brand image is a representation of the overall perception of the brand which is formed from the information and experience of the brand. Value perception is a consumer assessment that is carried out by comparing the benefits / benefits that will be received with the sacrifices incurred for a product. So this perception of value has an impact on consumers deciding to buy or use a product or service. This research is a quantitative descriptive study with the sample in this study being the consumers of Banana King Rengat. This study aims to determine and analyze the effect of service quality, brand image and perceived value on consumer loyalty. Questionnaires and interviews were conducted to obtain primary data and some additional data were used as primary data. The research findings indicate that service quality, brand image and perceived value have a positive influence on consumer loyalty to Pisang King Rengat.
\end{abstract}

Keywords: Service Quality; Brand Image; Perceived Value; Consumer Loyalty

\section{PENDAHULUAN}

Setiap perusahaan mengharapkan setiap konsumen memiliki loyalitas terhadap produk mereka. Loyalitas pelanggan sangat penting bagi perusahaan untuk menjaga kelangsungan hidup usahanya. Loyalitas adalah komitmen yang dipegang teguh untuk membeli ulang atau berlangganan dengan produk/jasa yang disukai secara konsisten dimasa datang. Konsumen yang loyal akan melakukan pembelian secara berulang-ulang dan sulit beralih ke merek lain (Tjiptono, 2005:32).

Kualitas layanan akan jadi satu faktor pembentuk konsumen loyal pada perusahaan. Menurut (Rasyid, 2017) jika anggapan pelanggan kepada layanan sesuai dengan yang_diharapkan, sebab itu kualitas pelayanan dipandang baik, tetapi ketika tanggapan konsumen terhadap pelayanan tidak seperti apa yang diharapankan, maka kualitas layanan dipandang buruk. Oleh sebab itu, layanan berkualitas bergantung kepada kemampuan jasa layanan agar selalu konsisten mencukupi apa yang harapankan konsumen. Saselah et al., tahun 2019 menilai kualitas layanan yang konsisten serta prima akan menunjukan kepada konsumen layanan yang digunakan ialah yang paling baik, sehingga menghasilkan penilaian yang memuaskan, mendorong konsumen untuk terus menggunakan layanan di masa mendatang dan membangun loyalitas konsumen (Saselah et al., 2019). Dalam riset yang dilakukan oleh Makanyeza mengatakan apabila kualitas layanan terus meningkat, pelanggan akan menjadi loyal (Makanyeza \& Chikazhe, 2017).

Dalam meningkatkan intensitas penjualan produk dalam pemasaran sangat penting untuk melihat perilaku konsumen dimana memiliki persepsi tentang seberapa besar kekuatan suatu produk yang akan dipakai. Dalam sistem perilaku konsumen ada beberapa pilihan atau selera yang dilakukan oleh para pembeli yang dapat dipelajari oleh perusahaan dalam memasarkan produknya yang salah satunya yaitu citra merek. Oleh karena itu apabila citra merek tersebut kuat maka akan berpengaruh terhadap loyalitas seorang konsumen dalam pembelian atau pemakaian suatu produk (Redo, 2018).

Konsumen cenderung membeli produk dengan merek yang sudah terkenal karena merasa lebih nyaman dengan hal - hal yang sudah dikenal, dengan adanya asumsi bahwa merek yang sudah dikenal lebih dapat diandalkan, selalu tersedia dan mudah dicari dan memiliki kualitas yang tidak diragukan, sehingga merek yang lebih dikenal lebih sering dipilih konsumen daripada merek yang tidak dikenali oleh konsumen. Oleh sebab itu perusahaan harus menciptakan, mengembangkan, dan menjaga citra merek yang baik di mata masyarakat agar dapat bersaing dengan pesaingnya. 
Menjaga citra merek juga merupakan strategi positioning untuk menanamkan merek perusahaan di benak konsumen. (Tanady, 2020).

Pisang King rengat sangat menyadari bahwa konsumen dengan tingkat loyalitas tinggi akan memberikan keuntungan yang sangat besar bagi perusahaan, dari segi keuangan konsumen akan berkontribusi banyak disebabkan pembelianya yang terus menerus dan dari segi pemasaran konsumen tersebut akan dengan senang hati membagi atau menceritakan kepuasan yang ia dapat dari produk tersebut kepada orang lain, dengan demikian perusahaan perlu menjaga konsumen dengan loyalitas tinggi untuk menjaga kelangsungan perusahaan di masa depan.Loyalitas konsumen bisa ditingkatkan melalui kepuasan konsumen dengan cara melampaui harapan konsumen (Boonlertvanich, 2011).

Lokasi Pisang King Rengat yang ada dipusat kota dengan berbagai variasi produk yang ditawarkan antara lain dari rasa, tampilan dan lain sebagainya merupakan satu nilai atau poin tambahan di mata masyarakat atau konsumen.

\section{METODE PENELITIAN}

Penelitian dilakukan dengan pendekatan kuantitatif. Populasi dalam penelitian adalah konsumen yang telah membeli produk pada Pisang King Rengat Tahun 2020 berjumlah 22.266 orang. Penarikan sampel dg metode purposive sampling, dgn kriteria konsumen yang telah melakukan transaksi pembelian pada Pisang King Rengat minimal sebanyak 2 kali. Dalam pengambilan sampel dalam penelitian ini, penulis menggunakan rumus Slovin, sehingga jumlah sampel yang didapat adalah sebanyak 100 responden. Teknik pengumpulan data dengan angket yang disebarkan ke responden dan wawancara dengan respomden yang memahami dengan variabel yang akan diteliti. Data yang dikumpulkan kemudian di analisis dengan analisis regresi jalur dilakukan untuk melihat hubungan variabel yang digunakan.

\section{HASIL DAN PEMBAHASAN}

\section{A. Uji Asumsi Klasik}

1. Uji Normalitas

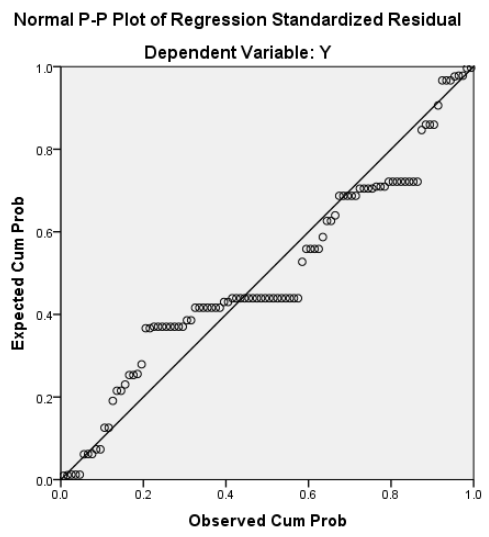

Gambar 1. Diagram Normalitas Data

Terlihat distribusi data mengikuti garis diagonal, artinya data mengikuti kriteria data normal.

2. Uji Multikolinieritas

Tabel 1. Tabel Hubungan

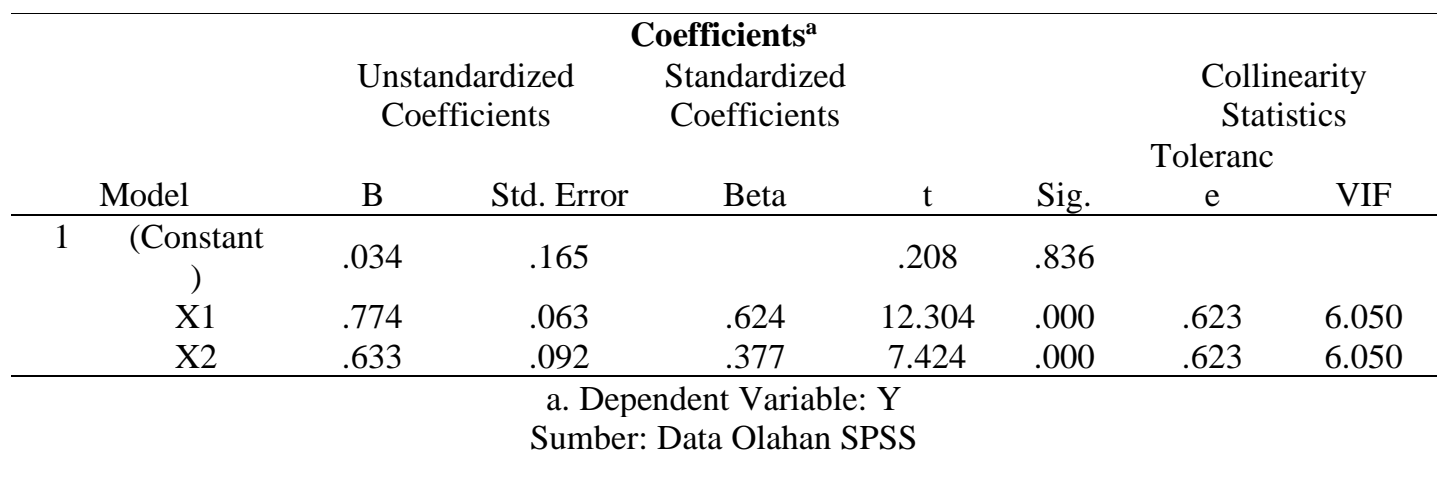

Nilai VIF sebesar 5,078 < 10 dengan nilai tolerance sebesar $0,197>0,10$. Sehingga dapat disimpulkan bahwa model regresi dalam penelitian ini tidak terjadi gejala korelasi antar variabel. 


\section{Uji Heteroskedastisitas}

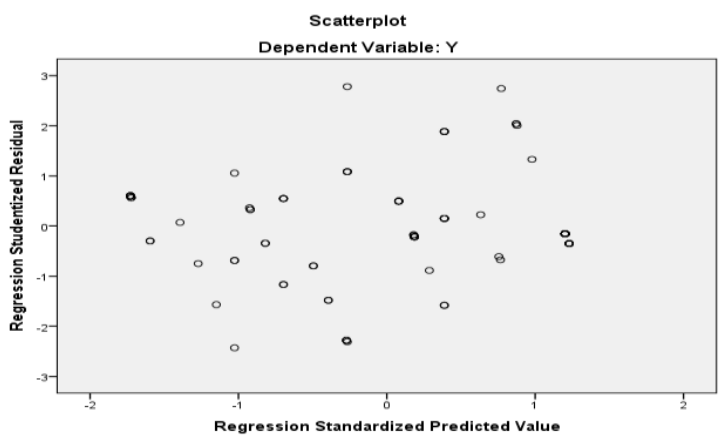

Gambar 2. Diagram Scatterplot

Titik-titik menyebar secara acak tidak membentuk pola tertentu yang jelas, serta tersebar diatas dan dibawah angka nol (0) pada sumbu Y. Oleh karena itu, dapat disimpulkan bahwa model regresi dalam penelitian ini bebas heteroskedasitas.

\section{B. Analisis Regresi linear Berganda}

1. Koefisien Korelasi ( R )

Skala kekuatan hubungan antar variabel sebagai berikut:

Tabel 2. Tabel Hubungan

\begin{tabular}{ll}
\hline Koefisien korelasi (r) & Hubungan \\
$0,00-0,199$ & Sangat rendah \\
$0,20-0,399$ & Rendah \\
$0,40-0,599$ & Sedang \\
$0,60-0,799$ & Kuat \\
$0,80-\ldots 1,0$ & Sangat kuat \\
\hline \multicolumn{2}{c}{ Sumber: Data Olahan SPSS }
\end{tabular}

Analisis data hasil penelitian menggunakan alat regresi linier berganda yang dijelaskan sebagai berikut:

Tabel 3. Koefesien SPSS

\begin{tabular}{llrrrrr}
\hline Model & \multicolumn{7}{c}{$\begin{array}{c}\text { Standardized } \\
\text { Unstandardized Coefficients } \\
\text { Coefficients } \\
\text { Beta }\end{array}$} & \multicolumn{1}{c}{ t } & \multicolumn{1}{c}{ Sig. } \\
\hline 1 & (Constant) & .264 & .268 & & .986 & .327 \\
& X1 & .394 & .059 & .492 & 6.657 & .000 \\
& X2 & .478 & .076 & .485 & 6.328 & .000 \\
X3 & .021 & .036 & .020 & .590 & .557 \\
\hline
\end{tabular}

Sumber: Data pengolahan SPSS

\section{Koefisien Determinasi $\left(\mathbf{R}^{2}\right)$}

Tabel 4. Model Summamry

\begin{tabular}{lcccc}
\hline \multicolumn{4}{c}{ Model Summary } \\
Model & $\mathrm{R}$ & R Square & $\begin{array}{c}\text { Adjusted R } \\
\text { Square }\end{array}$ & $\begin{array}{c}\text { Std. Error of the } \\
\text { Estimate }\end{array}$ \\
\hline 1 & $.989^{\mathrm{a}}$ & .978 & .977 & .59323 \\
a. Predictors: (Constant), X3, X1, X2 & & & \\
b. Dependent Variable: Y & & & \\
\hline
\end{tabular}

Angka R sebesar 0,989. Hal ini menunjukkan bahwa terjadi hubungan yang sangat kuat antara Kualitas pelayanan, Citra Merek dan Persepsi Nilai Terhadap Kepuasan Konsumen.

Koefisien Determinasi $\left(\mathrm{R}^{2}\right)$ menunjukkan besarnya pengaruh variable $\mathrm{X}$ terhadap variable $\mathrm{Y}$ secara bersama-sama dan dinyatakan dalam persentase. Pada table diatas menunjukan R Square sebesar 0,978, jika di persentasekan maka, $\mathrm{R}^{2}=0,978 ;(0,978 \times 100 \%)=97,8 \%$. Angka tersebut mempunyai arti bahwa sebesar 97,8 \% Loyalitas Konsumen dipengaruhi oleh variasi perubahan variabel Kualitas pelayanan (X1) Citra Merek (X2) dan Persepsi Nilai (X3), sedangkan sisanya $(100 \%-98,7 \%=1,7 \%)$ dipengaruhi oleh faktor-faktor penyebab lainnya yang tidak diteliti pada penelitian ini. 


\section{Uji Hipotesis}

Uji F (Uji Simultan)

Berikut adalah nilai F Hitung dalam Penelitian ini:

Tabel 5. Uji F

\begin{tabular}{|c|c|c|c|c|c|c|}
\hline \multicolumn{7}{|c|}{ ANOVAa } \\
\hline Model & & Sum of Squares & df & Mean Square & $\mathrm{F}$ & Sig. \\
\hline \multirow[t]{3}{*}{1} & Regression & 1508.215 & 3 & 502.738 & 1428.541 & $.000^{\mathrm{b}}$ \\
\hline & Residual & 33.785 & 96 & .352 & & \\
\hline & Total & 1542.000 & 99 & & & \\
\hline $\begin{array}{l}\text { a. Depe } \\
\text { b. Predi }\end{array}$ & $\begin{array}{l}\text { Adent Variabl } \\
\text { ctors: (Const }\end{array}$ & $\mathrm{X} 3, \mathrm{X} 1, \mathrm{X} 2$ & & & & \\
\hline
\end{tabular}

Sumber: Data pengolahan SPSS

Nilai Fhitung menunjukkan nilai sebesar 1428,541 dengan taraf signifikansi $F=0,00$. Dengan membandingkan nilai $F_{\text {hitung }}$ dan $F_{\text {tabel }}$ maka diperoleh sebuah kesimpulan. Cara menghitung $F_{\text {table }}$ adalah df $1=(k-1)$ dan df $2=(n-k)$ dimana (k) adalah jumlah variabel (bebas + terikat) dan (n) adalah jumlah observasi/sampel pembentuk regresi. Dan dapat dilihat pada kolom df1 dan df2 pada table F. Maka nilai df $1=(4-1)=3$ dan df2=(100 -4$)=96$ Dari hasil tersebut dapat diperoleh $\mathrm{F}_{\text {tabel }}=2,699$. Jadi dapat disimpulkan bahwa $\mathrm{F}^{\text {hitung }}>\mathrm{F}_{\text {tabel }}(1428,541>2,699)$. Nilai signifikansi adalah dibawah 0.05 yang menunjukkan bahwa variabel bebas secara Bersama-sama mempunyai pengaruh yang signifikan terhadap Loyalitas Konsumen pada signifikansi 5\%, Sig F $<5 \%(0,00<0,05)$.

Artinya bahwa secara bersama-sama Kualitas pelayanan, Citra Merek dan Persepsi Nilai berpengaruh signifikan terhadap Loyalitas Konsumen .

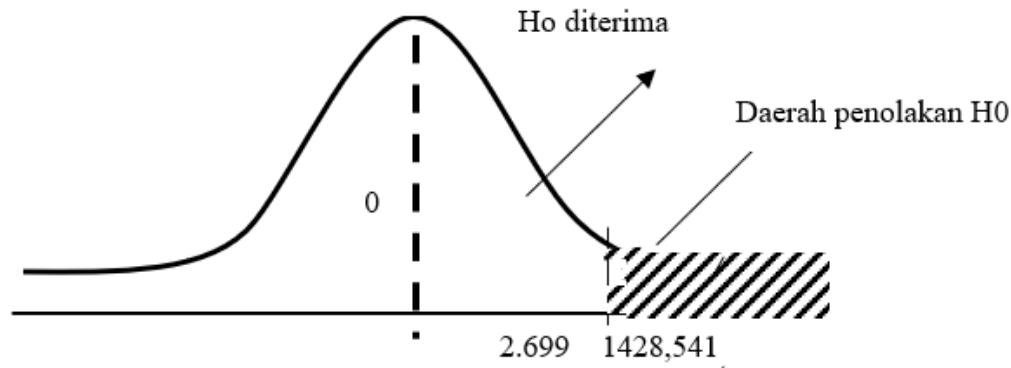

Uji t (Uji Parsial)

Gambar 3. Kurva Normal Uji F

Tabel 6. Hasil Uji t

\begin{tabular}{|c|c|c|c|c|c|c|}
\hline \multicolumn{7}{|c|}{ Coefficients $^{\mathrm{a}}$} \\
\hline \multirow[b]{2}{*}{ Model } & & Unstandardizec & Coefficients & $\begin{array}{l}\text { Standardized } \\
\text { Coefficients }\end{array}$ & & \\
\hline & & B & Std. Error & Beta & $\mathrm{t}$ & Sig. \\
\hline 1 & (Constant) & .264 & .268 & & .986 & .327 \\
\hline & $\mathrm{X} 1$ & .394 & .059 & 492 & 6.657 & .000 \\
\hline & $\mathrm{X} 2$ & .478 & .076 & .485 & 6.328 & .000 \\
\hline & X3 & .021 & .036 & .020 & .590 & .557 \\
\hline
\end{tabular}

a. Dependent Variable: Y

Sumber: Data pengolahan SPSS

Interpretasi terhadap persamaan tersebut beserta uji hipotesis akan diberikan dengan criteria sebagai berikut :

Ho : $\mathrm{t}_{\text {tabel }} \leq \mathrm{t}_{\text {hitung }} \leq \mathrm{t}_{\text {tabel, }}$, artinya tidak ada pengaruh antara Variabel Bebas dengan variabel terikat.

$\mathrm{Ha} ; \mathrm{t}_{\text {tabel }} \geq \mathrm{t}_{\text {hitung }} \geq \mathrm{t}_{\text {tabel, }}$, artinya ada pengrauh antara Variabel Bebas dengan variabel terikat.

$\mathrm{T}$ hitung dapat dilihat pada output hasil uji T. sementara t hitung sebagai berikut:

$\mathrm{t}$ tabel $=\mathrm{t} \alpha / 2(\mathrm{n}-2), \alpha=5 \%, \mathrm{n}=100$

$\mathrm{t}$ tabel $=\mathrm{t} 0,025(98)=1,98447$

\section{KESIMPULAN}

Koefisien Determinasi $\left(\mathrm{R}^{2}\right)$ menunjukkan besarnya pengaruh variabel $\mathrm{X}$ terhadap variable $\mathrm{Y}$ secara bersama-sama dan dinyatakan dalam persentase. Pada tabel diatas menunjukan $\mathrm{R}$ Square sebesar 0,978 , jika di persentasekan maka, $\mathrm{R}^{2}=$ 0,$978 ;(0,978 \times 100 \%)=97,8 \%$. Angka tersebut mempunyai arti bahwa sebesar 97,8\% Loyalitas Konsumen dipengaruhi oleh variasi perubahan variabel Kualitas pelayanan, Citra Merek (X1) dan Persepsi Nilai (X2), sedangkan sisanya $(100 \%-98,7 \%=1,7 \%)$ dipengaruhi oleh faktor-faktor penyebab lainnya yang tidak diteliti pada penelitian ini. 
$\mathrm{F}^{\text {hitung }}>\mathrm{F}_{\text {tabel }}(1428,541>2,699)$. Nilai signifikansi adalah dibawah 0.05 yang menunjukkan bahwa variabel bebas secara serempak mempunyai pengaruh yang signifikan terhadap loyalitas konsumen pada signifikansi 5\%, Sig $\mathrm{F}<5 \%$ $(0,00<0,05)$. Artinya bahwa secara bersama-sama kualitas pelayanan, citra merek dan persepsi nilai berpengaruh signifikan terhadap loyalitas konsumen. Untuk lokasi penelitian harus lebih memperhatikan beberapa aspek, antara lain aspek kreativitas dan persepsi nilai karena bisa meningkatkan kepuasan konsumen.

\section{REFERENCES}

Agustina, Ika Fitria. 2020. Pengaruh Persepsi Nilai dan Kepuasan Konsumen terhadap Loyalitas Konsumen Alfamart di Kota Mataram. Jurnal Binawakya Vol. 14 No.9.

Ariyanti,Kurnia dan Sri Setyo Iriani. (2014). "Pengaruh Persepsi Nilai dan Persepsi Resiko Terhadap Niat Beli Kosmetik Organik". Fakultas Ekonomi, Universitas Negeri Surabaya. Surabaya.

Aziz, Abdul. 2014. Perilaku Konsumen Dalam Prespektif Pemasaran. Jakarta: Lentera Ilmu Cendekia.

Gadau, Matias. 2016. Pengaruh Citra Merek (Brand Image) terhadap Loyalitas Konsumen Studi Kasus pada Produk Body Mist The Body Shop di Ambarukmo Plaza Yogyakarta. Skripsi. FE Universitas Sanata Dharma Yogyakarta.

Griffin, Jill (2015), Customer Loyalty : Menumbuhkan dan Mempertahankan Kesetiaan , Alih bahasa,Jakarta: Erlangga

Haryantini. 2019. Pengaruh Citra Merek dan Promosi terhadap Loyalitas Pelanggan Go-Jek di Stasiun Depok Jawa Barat. Jurnal Pemasaran Kompetitif Vol. 3 No. 1.

Hasan, A. 2015. Marketing dan Kasus-Kasus Pilihan. Yogyakarta: CAPS (Center for Academic Publishing Service).

Henriawan, Desan. 2015. Pengaruh Kualitas Pelayanan dan Kepuasan Pelanggan terhadap Loyalitas Pelanggan (Studi Kasus pada Toko Cabang Mufin Wilayah Bandung Timur). Jurnal Copetition Vol. VI No. 2.

Herwinarni, Yuniarti., Gunistiyo. 2002. Pengaruh Persepsi Nilai, Persepsi Kualitas, dan Citra Merek terhadap Loyalitas Konsumen pada Rumah Makan "Indonesia” di Kota Tegal. European Journal of Marketing Vol. 36 No. 7/8.

Kotler, Philip dan Kevin Lane Keller. 2018. Manajemen Pemasaran. edisi ke-18, jilid2. Erlangga: Jakarta

Nadra, Nyimas. 2017. Pengaruh Kualitas Pelayanan dan Kepuasan Pelanggan terhadap Loyalitas Pelanggan pada CV. Sinar Surya Palembang. Skripsi. FEB Universitas Muhammadiyah Palembang.

Rangkuti, Freddy. 2015. Analisis SWOT: Teknik Membedah Kasus Bisnis. Jakarta: PT. Gramedia Pustaka Utama.

Saleh, Sri Handayani., Hidayati, Tetra., dan Asnawati. 2020. Pengaruh Persepsi Nilai Pelanggan dan Kepuasan Konsumen terhadap Loyalitas Konsumen Citarasa Bakery Bontang. JIMM Jurnal Ilmu Manajemen Mulawarman Vol. 5 No. 4.

Setiawan,Danang. 2015. Perilaku Konsumen. Yogyakarta : Center of Academic Publishing Service.

Sinaga, Alif Ranita. 2016. Pengaruh Kualitas Pelayanan dan Citra Merek terhadap Loyalitas Pelanggan (Studi Pelanggan KFC, Metrocity Pekanbaru). JOM FISIP Universitas Riau Vol. 3 No. 2.

Sumarwan, Ujang. 2015. Perilaku Konsumen Teori Penerapannya Dalam Pemasaran Edisi Kedua. Cetakan Ketiga. Bogor: Penerbit Ghalia Indonesia.

Sutisna. 2015. Perilaku Konsumen dan Komunikasi Pemasaran. Bandung : PT. Remaja Rusdakarya

Teguh, Muhammad .2014. Metode Kuantitatif untuk Analisis Ekonomi dan Bisnis Ed. 1, Cet. 1.Jakarta: Rajawali Pers.

Tjiptono, Fandy. 2016. Total Quality Service. Andi Offset: Yogyakarta

Yunaida, Erni. 2017. Pengaruh Brand Image (Citra Merek) terhadap Loyalitas Konsumen Produk Oli Pelumas Evalube di Kota Langsa. Jurnal Manajemen dan Keuangan Vol. 6 No. 2 